\title{
Ductal Eccrine Carcinoma with Squamous Metaplasia
}

National Cancer Institute

\section{Source}

National Cancer Institute. Ductal Eccrine Carcinoma with Squamous Metaplasia. NCI

Thesaurus. Code C43347.

A variant of ductal eccrine carcinoma with squamoid metaplasia. 